East African Medical Journal Vol. 83 No. 10 October 2006

TRADITIONAL USE OF INDIGENOUS MOSQUITO-REPELLENTS TO PROTECT HUMANS AGAINST MOSQUITOES AND OTHER INSECT BITES IN A RURAL COMMUNITY OF CAMEROON

N.N. Ntonifor, PhD, Department of Biochemistry and Microbiology, C.A. Ngufor, MSc, H.K. Kimbi, PhD and

B.O. Oben, PhD, Department of Plant and Animal Sciences, University of Buea, P.O. Box 63, Buea, Cameroon

Request for reprints to: Dr. H.K. Kimbi, Department of Plant and Animal Sciences, University of Buea, P.O. Box 63, Buea, Cameroon

\title{
TRADITIONAL USE OF INDIGENOUS MOSQUITO-REPELLENTS TO PROTECT HUMANS AGAINST MOSQUITOES AND OTHER INSECT BITES IN A RURAL COMMUNITY OF CAMEROON
}

\author{
N.N. NTONIFOR, C.A. NGUFOR, H.K. KIMBI and B.O. OBEN
}

\begin{abstract}
Objective: To document and test the efficacy of indigenous traditional personal protection methods against mosquito bites and general nuisance.

Design: A prospective study based on a survey and field evaluation of selected plant-based personal protection methods against mosquito bites.

Setting: Bolifamba, a rural setting of the Mount Cameroon region.

Subjects: A structured questionnaire was administered to 179 respondents and two anti-mosquito measures were tested under field conditions.

Main Outcome Measures: Identified traditional anti-mosquito methods used by indigenes of Bolifamba. Two plants tested under field conditions were found to be effective.

Results: Of the 179 respondents, 88 (49. 16\%) used traditional anti-mosquito methods; 57 (64.77\%) used plant-based methods while $31(35.2 \%)$ used various petroleum oils. The rest of the respondents, $91(50.8 \%)$ used conventional personal protection methods. Reasons for using traditional methods were because they were available, affordable and lack of known more effective alternatives. The demerits of these methods were: labourious to implement, stain dresses, produce a lot of smoke/ repulsive odours when used; those of conventional methods were lack of adequate information about them, high cost and non-availability. When the two most frequently used plants, Saccharum officinarium and Ocimum basilicum were evaluated under field conditions, each gave a better protection than the control.

Conclusion: Most plants used against mosquitoes in the area are known potent mosquito repellents but others identified in the study warrant further research. The two tested under field conditions were effective though less than the commonly used commercial diethyltoluamide.
\end{abstract}

\section{INTRODUCTION}

Malaria remains robustly endemic in sub-Saharan Africa including Cameroon where the disease is prevalent throughout the year with transmission being affected by climate and geography $(1,2)$. To date, no sufficiently effective method has been found to control the high transmission rates in sub-Saharan
Africa $(3,4)$. Some of the methods to prevent and control malaria epidemics are the control of its mosquito vectors and personal protection using insecticide impregnated bed nets $(5,6)$ and insect repellents $(7,8)$.

Although diethyltoluamide (DEET) is the most widely used repellent, it is not effective against all insects (9) or easily available or affordable in most 
rural communities of Africa where it is most needed. Prior to the advent of the use of synthetic chemicals as repellents, humans used plant-derived substances to protect themselves against insect disease vectors (10) and general nuisance from biting insects. Plantderived repellents are cost-effective and sustainable alternatives to the synthetic chemicals. Different communities use different plants in various forms to protect themselves against mosquitoes and other insect bites (11). Ethnobotanical studies have been conducted elsewhere in Africa such as Nigeria (12), Zimbabwe (13) and Kenya (14) to collect information on the traditional uses of plants against mosquitoes and other insect bites. However, similar studies have been conducted in Cameroon though studies on the use of traditional methods to control agricultural pests (15) have been conducted. We therefore hypothesized that people living in rural or semiurban communities in Cameroon also use traditional approaches to protect themselves against mosquitoes or other insect bites and general nuisance given that the warm humid tropical climate of Cameroon is conducive for the rapid build up of insect populations in general. This study was therefore designed to conduct a survey to document the various methods employed by residents of Bolifamba and its environs to protect themselves against mosquitoes and other biting arthropods with particular reference to plant-derived repellents. Further objectives were to identify the various plants used by the residents of the village and to validate the effectiveness of selected methods through scientific experimentation.

\section{MATERIALS AND METHODS}

Description of study site: Bolifamba is a village in Southwest Cameroon at $247.89^{\circ} \mathrm{N}$ and $58.24^{\circ} \mathrm{E}$ and an altitude of $530 \mathrm{~m}$ on the east slope of Mount Cameroon. It is $25 \mathrm{~km}$ from the Atlantic Ocean and has a relative humidity of $80 \pm 10 \%$; a temperature range of $18-23^{\circ} \mathrm{C}$ with an annual rainfall of $4090 \mathrm{~mm}$. It has an equatorial climate with a rainy season (MidMarch to October) and a dry season (November to Mid-March). A slow flowing permanent stream flows across the village. A low-lying marshy area that permits the persistence of anopheline breeding all year round bounds the village on the southwestern side. It is essentially an agrarian community and the inhabitants are of several ethnic groups. There are two main house types - cement brick and plank (wood) houses that have breaks and crevices on the walls which mosquitoes exploit as hideouts and avenues to fly in and out of the houses.

Data collection: A structured questionnaire was administered to 179 inhabitants from the various quarters of Bolifamba and its environs. Individuals were interviewed at home in English and exceptionally in pidgin (broken English) while the interviewee filled the questionnaires so as to also cover illiterate inhabitants. The questions asked concerned what methods they used and how these were used to protect themselves against mosquitoes or other insect bites and general nuisance with particular reference to plants and plant-derived repellents. Questions were asked on how they got to know about such methods, why they decided to use them, how effective these were against mosquitoes and other insect bites and whether they experienced any side effects after using such methods. Socio-cultural data such as the sex, age, and educational level of the respondents was collected. The house type of each respondent was also noted as being cement brick or plank (wood) house. All plants mentioned were identified to obtain the scientific names and for those that could not be easily identified on the spot samples were taken to the Botany Programme of the Department of Plant and Animal Sciences, University of Buea, Cameroon, for expert identification.

Field evaluation of Saccharum officinarum and Ocimum basilicum juices: Based on the results of the survey, the two most frequently used plants, Saccharum officinarum and Ocimum basilicum were selected for field evaluation. Evaluation was done following the same method described by the respondents. Essentially, the stems and leaves of S. officinarum and O. basilicum each were crushed and the juice squeezed and used in the test. Water and diethytoluamide (DEET) were used as the negative and positive controls respectively. Four volunteers were recruited and briefed on the work and they gave an informal consent prior to being instructed on how to apply the repellents and count the mosquito bites. From preliminary studies on human landing catches at Bolifamba, 1900 to 2100 hours were adopted for the study. During the tests, the volunteers sat on wooden stools two metres apart. Each received one milliliter 
of the target test solution or control on each leg from the knee to the ankle. Each mosquito bite on the treated part of the leg was reported to the investigator who recorded it and the insect chased away. Every fifteen minutes, the subjects exchanged seats after the investigators had examined their leg with the aid of a flashlight in case there were mosquitoes that were not felt by the test subject. The experiment was stopped after two hours and repeated on four different days. The percent protection of each test solution was calculated as: \{(number of bites on control - number of bites on treated)/number of bites on control $\} \times 100$. The data were analysed using the students' t-test.

\section{RESULTS}

Use of anti-mosquito/insect methods: Out of 179 respondents, 88 (49.2\%) used traditional methods to protect themselves against mosquitoes and insect bites. Of those who used traditional methods, 57 $(64.8 \%)$ used plant based methods while 31 (35.2\%) used other materials like kerosene, engine lubricating oil or soil. Of the 179, 91 (50.8\%) did not use traditional personal protection methods though most of them used other conventional methods like aerosol insecticides, untreated bed nets or environmental management; seven $(4.0 \%)$ did not use any anti-mosquito or insect method (Table 1). In many cases, those who employed traditional methods used more than one plant species. Different plant parts such as leaves, stem barks, whole plants etc were used (Table 2). The most frequent reasons for using the traditional methods were that they were affordable, easily available and also lack of known more effective alternatives. Their disadvantages were that some methods were labourious to implement, stained dresses, and produced a lot of smoke or repulsive odours when used. The main demerits of more conventional methods were lack of adequate information about them, high costs and non-availability. At least $80 \%$ of the respondents had learnt about the remedies from parents or relatives (ancestors).

Table 1

Various anti-mosquito/insect methods used by respondents and their merits and demerits

\begin{tabular}{lccll}
\hline Method & No. & $(\%)$ & Merits & Demerits \\
\hline Untreated bed nets & 74 & 41.3 & Effective & Costly \\
Impregnated bed nets & 0 & 0.0 & Not known & Not available \\
Aerosol sprays/coils & 71 & 39.7 & Effective & Provokes cough and catarrh, costly \\
Aerosol sprays/bednets & 45 & 25.1 & Effective & Costly \\
Repellent creams & 11 & 6.1 & Effective & Costly, not easily available \\
Clearing of bushes & 15 & 8.4 & Practical & Labourious \\
Filling of pits & 3 & 1.7 & Practical & Labourious under heavy rains \\
Plants & 57 & 31.8 & Cheap and available & Produce smoke, some stain dresses, \\
& & & & some make skin dry \\
Others (petroleum oils etc) & 31 & 17.3 & Cheap and available & Produce smoke, some stain dresses \\
& & & & or have bad odours \\
Oils in water pools & 8 & 4.5 & not practical & Messy \\
Nothing & 7 & 4.0 & - & - \\
\hline
\end{tabular}

Many respondents used more than one method.

No. = number of people using the particular method 


\section{Table 2}

Plant types used by respondents in various mosquito/insect protection methods

\begin{tabular}{|c|c|c|c|c|}
\hline Plant type & Local name & Plant part used & No. & $(\%)$ \\
\hline Saccharum officinarum & Sugar cane & Stems & 32 & 56.1 \\
\hline Ocimum basilicum & Basil (massepo) & Leaves & 18 & 31.6 \\
\hline Elaeis guinnensis & Oil palm & $\begin{array}{l}\text { Palm nut/kernel oil } \\
\text { Palm nut/ kernel chaff }\end{array}$ & 15 & 26.3 \\
\hline Cestrum noctorum & Queen of the night & Whole plant & 5 & 8.8 \\
\hline Citrus sp. peels & Orange peels & Peels & 4 & 7.0 \\
\hline Khaya grandifolia & Mahogany & Leaves & 4 & 7.0 \\
\hline Cymbopogon citratus & Lemon (fever) grass & Leaves/stems & 2 & 3.5 \\
\hline Cupressus sp. & Cypress & Leaves & 2 & 3.5 \\
\hline Dacryodes edulis & Bush butter (plum) & Gum from tree bark & 2 & 3.5 \\
\hline Vernonia amygdalina & Bitter leaf & Leaves & 1 & 1.8 \\
\hline Unidentied plants & King grass/"malamfeu" & Leaves & 2 & 3.5 \\
\hline
\end{tabular}

Most respondents used more than one plant species.

Table 3

Brief description of how the various methods are used

\begin{tabular}{ll}
\hline Method/plant type & Method used \\
\hline Saccharum officinarum & Skin application of juice \\
Ocimum basilicum & Skin application, whole plant, direct burning \\
Elaeis guinnensis (chaffs) & Skin application, direct burning with Ocimum sp. \\
Cestrum noctorum & Live plant \\
Citrus sp. peels & Skin application, direct burning \\
Khaya grandifolia & Skin application \\
Cymbopogon citratus & Skin application \\
Cupressus sp. & Direct burning \\
Dacryodes edulis & Direct burning of oil from tree bark' \\
Vernonia amygdalina & Skin application \\
Unidentied plants & Skin application/whole plants \\
Soil from termite nests & Direct burning \\
Kerosene & Skin application \\
Engine lubricating oil & skin application \\
\hline
\end{tabular}

Description of mode of application of various personal protection methods: Respondents described three main ways of applying the various methods. These were direct burning of a single or a mixture of target materials to produce repellent smoke in house to drive away mosquitoes, crushing and rubbing of plant juice on the body or the rubbing of petroleum oils (kerosene and engine lubricating oils) on the bodies as repellents and planting of a target plant around the house (live plant) to repel mosquitoes (Table 3).

Socio-cultural characteristics of the respondents: All respondents who had information on traditional anti-mosquito/insect methods were above 25 years; generally younger persons knew little or nothing about such methods. Similarly, respondents who lived in cement brick houses did not know much 
Table 4

Socio-cultural characteristics of the study population

\begin{tabular}{lcccc}
\hline \multirow{2}{*}{ Parameter } & Used traditional methods & \multicolumn{3}{c}{ Used conventional methods or nothing } \\
\hline Residing in wooden houses & No. & $(\%)$ & No. & $(\%)$ \\
Residing in brick houses & 70 & 79.5 & 53 & 58.2 \\
Never been to school & 18 & 18.5 & 38 & 41.8 \\
Attended at least primary School & 19 & 21.6 & 11 & 12.5 \\
& 69 & 78.4 & 77 & 84.6 \\
\hline
\end{tabular}

Table 5

Repellent activitties of Ocimum basilicum, Saccharum officinarum and diethytoluamide (DEET) in Bolifamba

\begin{tabular}{lccccc}
\hline Treatment & $\begin{array}{c}\text { Mean no. of bites (SE) } \\
\text { No. }\end{array}$ & $\begin{array}{c}\text { Average protection } \\
(\%)\end{array}$ & Ratio to DEET & p-value \\
\hline O. basilicum juice & 15 & 5.1 & $39^{\mathrm{a}}$ & 0.45 & 0.001 \\
S. officinarum juice & 12 & 3.2 & $52^{\mathrm{b}}$ & 0.60 & 0.002 \\
DEET & 3 & 1.4 & $87^{\mathrm{c}}$ & 1.00 & 0.000 \\
Control (water) & 24 & 6.8 & & & \\
\hline
\end{tabular}

p-values for the comparison of mean of each treatment and that of control by t-test.

Values followed by the same letter are not significantly different.

about such methods while $70(79 \%)$ of those who used such methods lived in wooden houses. Those who used traditional methods were $55.7 \%$ and $54.3 \%$ males and females respectively and $78.4 \%$ of them had attended at least primary school education (Table 4).

Field evaluation of Saccharum officinarum and Ocimum basilicum juice: Each of the juices of S. officinarum (sugar cane) and O. basilicum (massepo) gave a better percent protection than the control. S. officinarum juice was better than $O$. basilicum but neither was as good as DEET (Table 5). It was also observed that after two hours of exposure, the effectiveness of these plant juices decreased significantly.

\section{DISCUSSION}

The use of untreated bed nets was the most popular protective measure against mosquitoes among the more affluent respondents while plant-based measures were more common among the less affluent who were predominantly peasant farmers. This was expected given that one of the main disadvantages of the conventional methods to the largely agrarian poorer segment of the population was their costly nature. Possibly if these conventional methods are provided free or at subsidised rates, the majority of the population will adopt them. Insecticide treated bed nets; a classical mosquito vector control strategy (5) is currently not being used by residents of Bolifamba due to unavailability and the lack of sensitisation about the usefulness of this method.

The unavailability and relatively costly nature of the conventional anti-mosquito/insect protection methods definitely mitigated in favour of the low cost plant-based methods. It will therefore be necessary to test the validity of the methods mentioned herein through scientific experimentation and even improve on their mode of application and vulgarise them to other areas. The two methods tested in the study under field conditions were not as effective as DEET possibly due to their methods of application. It would be important to fractionate extracts from these plants and test the various fractions. However, some of the plants such as Cymbopogon citratus (10), Citrus sp. peels $(16)$, Ocimum spp $(14,17)$ have already been shown to be effective mosquito repellents. Potent 
repellent plants may have potential for integration with untreated bed nets (18) and/or work complimentarily with other classical anti-mosquito/ insect methods. The main modalities of applying the different methods is by skin application and direct burning which have the disadvantages of drying up the skin and/or producing choking smokes. It would be important that after validating the effectiveness of these methods alternative modalities of application such as thermal expulsion in charcoal pots should also be tested (19) since the charcoal will reduce the amount of smoke produced. More occupants of wooden houses used anti-mosquito/insect methods irrespective of whether they were traditional or conventional methods. This is consistent with previous studies (20), which showed that mosquito populations and malaria prevalence were higher in wooden houses and their occupants respectively.

Further studies on the various anti-mosquito/ insect methods documented in this study are required in order to elucidate alternative complementary methods of protecting humans against disease vectors especially mosquitoes and general nuisance from other insects. These plantbased methods are cost-effective, easily available and may not require any external input in order to exploit them.

\section{REFERENCES}

1. WHO. Facts Sheets. 1998; 24: 8pp.

2. Snow R.W., Craig M., Deichmann U., et al. Estimating mortality, morbidity and disability due to malaria among Africa's non-pregnant population. Bull. Wld. Hlth. Org. 1999; 77: 624-640.

3. Lengeler C., Armstrong-Schellenberg J. and D'Alessandro U. Relative versus absolute risk of dying reduction after using insecticide treated bed nets for malaria control in Africa. TM \& JH. 1998; 3: 123-124.

4. Killen G.F., Mckenzie F.E., Foy B.D., et al. The potential impacts of integrated malaria transmission control on entomological inoculation rate in highly endemic areas. Am. J. Trop. Med. Hyg. 2000; 62: 545-555.

5. Lengeler C. and Snow R.W. From efficacy to effectiveness: insecticide treated bed nets in Africa. Bull. Wld. Hlth. Org. 1996; 74: 325-332.

6. Schenllenberg J.R., Abdulla S., Nathan R., et al. Effect of large-scale social marketing on insecticide treated bed nets on child survival in rural Tanzania, Lancet. 2001; 357: 1241-1247.
7. Curtis C.F., Lines J.D., ljumba J., et al. The relative efficacy of repellents against mosquito vectors of disease. Med. Vet. Ent.; 1: 109-119.

8. Gupta R.K. and Rutledge L.C. Roll of repellents in vector control and disease prevention. Am. J. Trop. Med. Hyg. 1994; Suppl. 50: 82-86.

9. Rojas E. and Scorza J.V. The use of lemon essential oil as a sandfly repellent. Trans. Roy. Soc. Trop. Med. Hyg. 1991; 85: 803-805.

10. Curtis C.F., Baolin L. and Renz A. Natural and synthetic repellents. Appropriate technology in vector control. Boca Raton, Fl. USA: CRC press, 75-90.

11. Hebbalker D.S., Hebbalker G.D., Sharma R.N., et al. Mosquito repellent activity of oils from Vitex negundo Linn. Leaves. Indian J. Med. Res. 1992; 95: 200-203.

12. Afolabi B.M. Knowledge, attitude and practice of malaria in isolated community on the Atlantic Coast of Lagos, Nigeria. Malaria Infect. Dis. 1996; 4: 6-13.

13. Lukwa N., Nyazema N.Z., Curtis C.F., et al. People's perception about malaria transmission and control using mosquito repellent plants in a locality in Zimbabwe. Centr. Afr. J. Med. 1999; 45: 64-68.

14. Seyoum A., Palsson K., Kung'a S.'et al. Traditional use of mosquito-repellent plants in Western Kenya and their evaluation in semi-field experimental huts against Anopheles gambiae: Ethnobotanical studies and application by thermal expulsion and direct burning. Trans. Roy. Soc. Trop. Med. Hyg. 2002; 96: 225-231.

15. Parh I.A., Forbuzo B.C., Matheney E.L., et al. Plants used for the control of insect pests on stored grains in parts of the North West Highlands Savanna zone of Cameroon. Sci. Agron. Dev. 2001; 1: 54-60.

16. Ezeonu F.C., Chidume G.I. and Udedi S.C. Insecticidal properties of volatile extracts of orange peels. Bioresource Technology. 2001; 76: 273.

17. Pathak N., Mital P.K., Singh O.P., et al. Larvicidal action of essential oils from plants against the vector mosquitoes Anopheles stephensi (Liston) Culex quiquefasciatus (Say) and Aedes aegypti (L). Int. Pest Control. 2000; 42: 53-53.

18. Takken W. Do insecticide-treated bed nets have an effect on malaria vectors? TM E $l H .2002 ; 7: 1022-1030$.

19. Seyoum A., Killen G.F., Kabiru E.W., et al. Field efficacy of thermally expelled or live potted repellent plants against African malaria vectors in Western Kenya. TME lH. 2003; 8: 1005-1011.

20. Ndukum M.B. Relating entomological, environmental and demographic parameters with malaria prevalence and parasite density. MSc. Theses, University of Buea, Cameroon. 2004 62pp. 